\title{
De kerkelijke subsidies in de Nederlanden onder Karel V (1532-
} 1555)

\section{Baelde}

\section{Citer ce document / Cite this document :}

Baelde M. De kerkelijke subsidies in de Nederlanden onder Karel V (1532-1555). In: Revue belge de philologie et d'histoire, tome 43, fasc. 4, 1965. Histoire (depuis la fin de l'Antiquité) - Geschiedenis (sedert de Oudheid) pp. 1243-1271; doi : https://doi.org/10.3406/rbph.1965.2603

https://www.persee.fr/doc/rbph_0035-0818_1965_num_43_4_2603

Fichier pdf généré le 13/04/2018 


\section{DE KERKELIJKE SUBSIDIES IN DE NEDERLANDEN ONDER KAREL V (1532-1555)}

In het kader van de financiële geschiedenis van de zestiende eeuw vormen de kerkelijke subsidies een volkomen afzonderlijk hoofdstuk.

Tijdens de regering van $\mathrm{Karel} \mathrm{V}$ waren de gewone inkomsten in de Nederlanden de domaniale opbrengsten en de belangrijke geldsommen van de veelvuldige gewone en buitengewone beden. Daarnaast kon de Keizer nog zijn toevlucht nemen tot leningen en verpanding of verkoping van domeingoederen. Slechts uitzonderlijk kon Karel V nog nieuwe financieringsmiddelen voorzien.

In dit opzicht moet men de kerkelijke subsidies wellicht als het beste voorbeeld beschouwen. Deze belangrijke lasten op de kerkelijke beneficiën werden in de jaren 1532, 1542, 1546 en 1552 door pauselijke bullen opgelegd ( ${ }^{\mathbf{1}}$ ).

In dit artikel krijgt men nauwkeurige gegevens betreffende de voorbereiding, de uitvoering en de werkelijke opbrengst van deze kerkelijke subsidies. Tevens wordt de betekenis van deze speciale belastingen voor de staatsfinanciën in de betrokken periode geschetst.

(1) Enkele verspreide gegevens over de hier behandelde subsidies vindt men bij A. Henne, Histoire du règne de Charles-Quint en Belgique, Brussel, 1858-1860, d. 6, p. 71 ; d. 8, pp. 48, 281. Ook P. GoRIssen, De prelaten van Brabant onder Karel V (1515-1544). Hun confederatie (1534-1544), in Standen en Landen, 1953, d. 6, pp. 56-57, verstrekt een paar inlichtingen en verwijst daarenboven naar enkele interessante archiefnummers uit het Brusselse Rijksarchief. Deze stukken - die door ons werden geraadpleegd behoren tot het fonds van de Audiëntie, namelijk de nummers 42, 47, 52, 53 en 63. De kerkelijke subsidies na 1530 werden door E. De MOREAU, Histoire de l'église en Belgique, 1949, d. 4, p. 198, volledig over het hoofd gezien. 
Tenslotte wordt het uitzonderlijk karakter van deze kerkelijke bijdragen kort toegelicht $\left.{ }^{(}\right)$.

\section{***}

De eerste - hier besproken - heffing op de inkomsten van de geestelijkheid in de Nederlanden werd door paus Clemens VII op 11 september 1532 aan Karel $V$ toegestaan. Op deze datum werd een bul uitgevaardigd waarbij de Keizer in zijn erflanden bij alle geestelijken het inningsrecht verkreeg van de helft der inkomsten van de beneficiën die vierentwintig gulden per jaar overtroffen; de beneficiën die tussen twaalf en viercntwintig gulden 's jaars opbrachten werden voor twee tienden belast; de inkomsten van minder dan twaalf gulden werden van iedere heffing vrijgesteld $\left({ }^{2}\right)$. De bedelorden vielen niet onder deze aanslagen. De pauselijke bul was het concreet resultaat van een door Karel V reeds vroeger geuit plan om zijn aktie tegen de Turken gedeeltelijk te laten financieren door een speciale taks op de inkomsten van de geestelijkheid. In een brief van 27 maart 1532 uit Regensburg schrijft de Keizer aan de landvoogdes Maria van Hongarije : «... Et après avoir tout bien considéré et pesé, je treuve et me semble que le plus convenable, apparant, juste, raisonnable et tollérable moyen, considéré l'affère en soy, qualité d'icelluy, pour le soubstènement de nostre saincte foy et mère église et deffension de la ré-

(1) In deze bijdrage werden volgende afkortingen gebruikt : A.R.A., Algemeen Rijksarchief (Brussel) ; Aud., Papiers d'État et de l'Audience ; A.D.N., Archives Départementales du Nord (Rijsel) ; Rekenk., Rekenkamer ; H.H.S.A., Haus- Hof- Staatsarchiv (Wenen) ; P.A., Politisches Archiv; G.R.K., Grafelijkheidsrekenkamer (Den Haag); R.F., Rekeningen Fruin (Middelburg).

(2) Een kopie van die pauselijke bul bevindt zich te Brussel, A.R.A., Aud., nr. 776/1 ; een andere kopie treft men aan op het eerste blad van de rekening van het subsidie voor Holland; Den Haag, G.R.K., nr. 2538. Ook Henne, op. cit., d. 6, p. 71, geeft diezelfde inlichtingen en schrijft : « Le clergé, atteint par les aides, irrité des restrictions apportées à ses immunités, avait vu avec douleur une bulle du 11 septembre 1532 accorder à Charles-Quint l'autorisation de lever en subsides ecclésiastiques, dans les Pays-Bas, la moitié de la valeur de tous les bénéfices, tant réguliers que séculiers, d'un revenu annuel de 24 ducats ; et les deux dixièmes de cette valeur, pour les dignités et bénéfices du revenu de 12 à 23 ducats". 
publicque chrestienne, est de soy ayder et succourir des biens temporels ecclésiastiques tant par imposicions sur iceulx que vendaiges et engaigemens de quelque portion en fond et propriété et perception de bonne partie du revenu, mesmes de ce que surmonte leur raisonnable et nécessaire entretenement ... tenant pour certain que nostre saint père le pape, ayant à cueur (commil doit) ceste résistance et deffension contre ledit Turcq, et bien véant la très grande importance et inexcusable nécessité, le commandera et baillera en ce toute l'auctorité, faculté, permission et consentement requis... » (1). In diezelfde brief maant Karel $\mathrm{V}$ de landvoogdes Maria van Hongarije dan ook aan om die kwestie te behandelen « avec les bons personnaiges de par de là...».

De benarde financiële toestand van de staatsfinanciën was in 1532 niet nieuw. Tijdens het verblijf van de Keizer in de Nederlanden in 1531 werd er over deze moeilijkheid beraadslaagd maar men had er geen definitieve oplossing voor gevonden. Maria van Hongarije, de zuster van Karel V, eerst sinds 1 oktober 1531 met de landvoogdij belast, kreeg van meet af met het zwaarste probleem af te rekenen ( ${ }^{2}$ ). Op 18 april 1532 stuurde zij uit Antwerpen een antwoord aan Karel V waarbij zij voorstelde eerst de pauselijke bul af te wachten, " aultrement la poursuyte vous seroit infructueuse et encoires avec icelles [bulles] aures bien affère d'en prouffiter si n'aves bons commissaires et semble mieulx convenir estrangiers que du pays..." $\left({ }^{3}\right)$.

Het duurde nog tot 11 september vooraleer Karel V door de pauselijke bul alle volmachten voor zijn erflanden verkreeg. Daarmede waren echter niet alle moeilijkheden van de baan. Integendeel ! Zoals de landvoogdes het trouwens voorzien had, moesten nu vele maatregelen getroffen worden voor de praktische uitvoering van de bul. De belasting op de kerkelijke goederen was, zoals alle financiële maatregelen tegenover de Staten, een zeer delikate aangelegen-

(1) Brussel, A.R.A., Aud., nr. 52, fos 47v0-48.

(2) Voor meer inlichtingen daarover, zie onze studie: Financiële Politiek en domaniale evolutie in de Nederlanden onder Karel Ven Filips II, in Tijdschrift voor Geschiedenis, 1963, d. 76, pp. 14-30. Hierbij stellen wij er prijs op Drs. K. Maddens van harte te bedanken voor de interessante archiefverwijzingen die hij ons voor bovenvermeld artikel heeft bezorgd.

(3) Brussel, A.R.A., Aud., nr. 52, f० 57vo. 
heid. Reeds dadelijk na het nieuws van de pauselijke uitvaardiging kwam de geestelijkheid van de Nederlanden in beweging ${ }^{1}{ }^{1}$. Het is duidelijk dat geen enkel vertegenwoordiger van die bevoorrechte stand zich over die innovatie kon verheugen. Het kwam er dus op aan alle mogelijke reacties van de geestelijkheid op te vangen $\left({ }^{2}\right)$ en alle eventuele betwistingen of oppositietendenzen kordaat tegen te gaan.

Tot algemeen executor van het kerkelijk subsidie in de «landen van herwertsovere» werd Jan Carondelet, aartsbisschop van $\mathrm{Pa}$ lermo, aangesteld. Als hoogste kerkelijk hoogwaardigheidsbekleder in de Nederlanden kon Carondelet aan de nieuwe subsidie ongetwijfeld een hoge morele steun geven. Even belangrijk echter voor de Keizer en de landvoogdes was zijn positie in het centrale bestuur. Carondelet was immers reeds sedert 1522 hoofd van de Geheime

(1) De oprichting van een confederatie door de Brabantse prelaten stond, volgens P. GORISSEN, art. cit., pp. 56-57, in direkt verband met het kerkelijk subsidie. Zie daarover ook E. Valvekens, Een Premonstratenzerabdij in het begin der zestiende eeuw, Brussel, 1936, pp. 70-72. Over de oppositie van de Friese geestelijkheid, raadplege men J. S. Theissen, Centraal Gezag en Friesche Vrijheid. Friesland onder Karel V, Groningen, 1907, pp. 273-274.

(2) Op 24 november 1532 schrijft Karel V uit Mantua volgende interessante brief aan de landvoogdes Maria : «... Quant à l'exécution de la bulle pour recouvrer l'ayde et subside sur les ecclésiastiques en mes pays de pardelà, je treuve très bon ce qu'avez advisé ordonné et pourveu de députer en chacun diocèse ung commissaire afin de relever les prélatz et clergié du travail que ce leur feroit, que les convoqueroit tous à une fois et ne fais doubte que les personnages par vous à ce commis, que je tiens bien ydoines, convenables et expérimentez, feront en leur charge tel et si bon devoir et diligence que lesditz prélatz et clergé se monstreront raisonnables et contribueront libéralement audit ayde et subside, considéré mesinement que c'est pour le servicc de Dicu, deffension de notre saincte foy, bien, repoz et tranquilité de la chrétienneté et aussi les très grans et inextimables frais que j'ay suppourté et convient encoires faire contre le Turcq, tant par terre que par mer, comme je confie lesdits commissaires le sauront bien remonstrer et donner entendre esdits prélats et clergé, selon les mesmoires que sur ce leur pourrez faire bailler ; et touchant la difficulté que l'on doubte vouldroient allegher lesdits ecclésiastiques sur ce que par ladite bulle sembleroit que notre saint père n'auroit chargé, sinon la haulte et basse Germanie, combien que cela soit vuidez par la clause comprenant les pays et seigneuries à moy escheuts par succession de mes prédécesseurs, si feray-je, moy estant à Boloigne devers Sa Sainteté, pourveoir à ce, suivant le mémoire latin que m'avez envoyé et cependant vous recommande de faire en ce, tout comme j'en ay la confidence.» Brussel, A.R.A., Aud., nr. 47, fos 172v0-173. 
Raad en op 1 oktober 1531 werd hij praktisch ook voorzitter van de nieuwe Raad van State; hij was dus, na de Keizer en de landvoogdes, de meest invloedrijke figuur in de regering van de Nederlanden ( $\left.{ }^{1}\right)$. Tenslotte had Carondelet ook reeds veel ervaring betreffende kerkelijke subsidies opgedaan toen hij in 1529 de funktie van commissaris-generaal van de kruistocht tegen de Turken had vervuld ( ${ }^{2}$ ).

De eerste opdracht van Carondelet was de bul kracht van wet te verlenen door de bekendmaking. Deze procedure greep plaats in ieder bisdom afzonderlijk, met name dus in de bisdommen $\mathrm{Ka}$ merijk, Doornik, Atrecht, Luik, Utrecht en Terwaan. Deze taak werd door Carondelet aan ondergeschikten opgedragen. Voor het bisdom Atrecht bijvoorbeeld werd Marcq Lauwerin, deken van het St. Donaas-Kapittel te Brugge, aangeduid terwijl de deken van de St. Pieterskerk te Leuven, Nicolaas Coppijn de Montibus, zich van deze taak kweet in het bisdom Utrecht $\left({ }^{3}\right)$. Het is overduidelijk dat deze bekendmakingen zorgvuldig werden voorbereid en slechts aan zeer handige en betrouwbare provinciale afgevaardigden werden toegewezen $\left(^{4}\right)$. Op deze vergadering werd immers ook de propositie gedaan aan de geestelijkheid die alsdan een zekere tijd kreeg om antwoord te geven. De analogie met de procedure bij een bedeaanvraag valt hier dan ook ten zeerste op $\left(^{5}\right)$.

(1) Voor een korte levensschets, zie Biographie Nationale, d. 3, p. 348.

(2) Zie F. Remy, Les grandes indulgences pontificales aux Pays-Bas à la fin du Moyen-Age (1300-1531). Essai sur leur histoire et leur importance financière, Leuven, 1928, p. 202.

(3) In de rekening van Antoine de Landas, " receveur des transports de Flandres", aangesteld tot collecteur « sur les gens d'église et clergé des diocèses estans et ressortissans es villes de Bruges, Le Franc, L'Éscluse et autres petites villes circonvoisines...» treft men een post aan van 100 pond voor « maistre Marcq Lauwerin, doien du chappittre de l'église collégiale de Saint Donaes à Bruges ... pour ses despens et vaccations d'estre allé par ordonnance de la Majesté de la royne et substitucion de monseigneur l'archevesque de Palerme, de Bruges à Arras, pour insigner et donner à congnoistre à ceulx du clergié du diocèse et éveschié dudit Arras, lors à ceste cause assemblée, le contenu de la bulle et indult dudit subside...». Brussel, A.R.A., Rekenk., nr. 16107, fo 13. Voor de deken van St. Pieters te Leuven, ibidem, nr. 15755, p. 16 en H. DE Vocht, History of the collegium trilingue Lovaniense, d. 1, pp. 404 en 564, d. 2, p. 282.

(4) Zie daarover de brief van 24 november 1532 ; A.R.A., Aud., nr. 47, fo 172vo.

(5) In 1534 werd twintig pond betaald aan « Meester Jaspar Lievensz., eerste raidt van de raedt van den Keyser tot Uuytrecht, die opten IX $^{\text {en }}$ dach van september XXXIII gecomen is geweest van Uuytrecht alhier in den Hage, omme de vergaderinge die daer 
Een tweede zorg van Carondelet was de taxatie van de betrokken belastingsplichtigen. Deze taxatie was uiteraard een zeer belangrijke taak omdat hiervan in grote mate het succes van de kerkelijke belasting afhankelijk was.

Op 28 oogst 1533 werden daartoe speciale instructies uitgevaardigd waarbij alle mogelijke toepassingsmoeilijkheden van de taxatie door de landvoogdes Maria van Hongarije duidelijk werden opgelost. Aldus werden beslissingen getroffen betreffende de renten, pensioenen, onderhoudskosten en andere speciale lasten van de kerkelijke instellingen. De algemene strekking van deze instructies komt duidelijk naar voren in de laatste apostille van de landvoogdes : « Le tout sera ordinairement tauxé sans en riens rabatre ne déduire, non obstant que par l'instruction signée par la Royne avant ceste mémoire aucunement soit dit au contraire que a esté fait par abuz» $\left({ }^{1}\right)$.

De taxatie zelf werd hoofdzakelijk door verscheidene ambtenaren van de verschillende rekenkamers voorbereid. Daarvoor werd de geestelijkheid op een speciale vergadering bijeengeroepen waarbij zij dan uitgenodigd werd om de staten van haar inkomsten naar de Rekenkamer te sturen $\left({ }^{2}\right)$. Aldaar werden dan door een speciaal aangeduide ambtenaar de vele dokumenten verzameld waarna door de Raad van Financiën de belastingskohieren opgesteld werden $\left({ }^{3}\right)$.

wesen soude van den prelaeten, collegiën, cloesters ende andere geestelicke luyden ende t'ontfangen hueren antwoert upte proposicie hemluyden gedaen bijden deecken van Loven als gesubdelegeerde onder mynen heere den eerstbiscop van Palermen, om de subsidie den Keyzer geaccordeerd by onsen heylighen vader den paus int bisdom van Uuytrecht, in 't welck doende avermits dat zy nyet al en quamen opten prefixen dach totten XVI'n dach der voors. maent, daer inne begrepen zijn wederomme keeren tot Uuytrecht... s. Den Haag, A.R.A., G.R.K., nr. 3538, fo 22.

(1) Rijsel, A.D.N., B, 19259. Deze instructies werden gepubliceerd door D. BrouWERs, Les aides et subsides dans le comté de Namur au XVI• siècle, Namen, 1934, pp. 30-34.

(2) De denombrementen van vele gewesten zijn bewaard gebleven. Zie Brussel, A.R.A., Rekenk., nrs. 614, 615, 616, 617 en 618 . Voor Namen, zie D. Brouwers, op. cit., pp. 35-82.

(3) Aan Jacques Fevrier, rekenmeester bij de Rekenkamer te Rijsel, werd door Karel $V$ een som van 113 pond toegestaan « tant en considération des services que ledit maistre Jacques lui a faiz parchidevant en sondit estat comme pour aucunnement le recompenser des despens et fraiz extraordinaires par lui soustenuz en chariages durant les dernières nesges et geslées que aultrement en la commission qu'il a eue puis nagaires pour 
Deze taxaties werden vervolgens door Carondelet nagezien en onder zijn handtekening rechtsgeldig verklaard. De meeste taxaties werden opgesteld en goedgekeurd in de loop van de jaren 1533, 1534 en in de eerste helft van het jaar 1535. Toch vindt men nog taxaties van latere datering ${ }_{(}^{(1)}$. Hieruit blijkt dus dat het geruime tijd duurde vooraleer met de inning van het kerkelijk subsidie kon van wal gestoken worden en dat er nog meer tijd verstreek vooraleer de gehele belasting van de baan was.

Wie was er nu met het innen van het kerkelijk subsidie belast?

In tegenstelling met de veronderstelling dat de geestelijkheid zelf hiervoor zou instaan, werd deze taak opgedragen aan het bestaande kader van functionarissen in dienst van Karel $V$. Uiteraard nam men hierbij zijn toevlucht tot het ambtenarenkorps dat in gewone omstandigheden ook met financiële en fiscale zaken belast was. In die zin is het vanzelfsprekend dat aan de Raad van Financiën het algemeen beheer werd toegewezen. Vooral de ontvanger-generaal van Financiën speelde hierin een zeer actieve rol. Op zijn aanwijzingen benoemde Carondelet de collecteurs van het kerkelijk subsidie. Meestal werden hiervoor de plaatselijke ontvangers van het domein of van de beden benoemd $\left({ }^{2}\right)$. Het was ook de ontvan-

veoir et visiter les comptes, registres et papiers sur ceulx du clergié de pardecha au diocese de Tournay touchant les deniers venant de la tauxe du subside cy devant nommé, en chariant de ville $a$ aultre, pour sur les estatz qu'il en feroit asseoir ladite tauxe par le commissaire général et pour aultres causes à ce le mouvans, oultre et pardessus ses gaiges et la tauxe ordinaire à lui faicte et ordonnée pour ses journées vacqués oudit voiage... ». Brussel, A.R.A., Rekenk., nr. 16106, fo 19. De taxatie voor Artesië bijvoorbeeld werd verricht door Hughes de Grammez, heer van Wingene, gecommiteerde in de Raad van Financiën. Ibidem, nr. 618, fo. 1 .

(1) In de dekenij Gent werd de eerste taxatie op 30 oktober 1533 uitgevaardigd, de vijfde en laatste taxatie op 10 mei 1534. Brussel, A.R.A., Rek., nr. 16106, fo 1 en fo 12 . In Antwerpen is de eerste taxatie van 3 januari 1534; de negende en laatste aanslag is gedateerd op 5 augustus 1535. Idem, nr. 15768, for 1-16. De laatste taxatie te Brussel is van 24 november 1536, Idem, $\mathrm{nr}$. 15762, fo 32. In Zuid-Holland is de laatste taxatie van 16 januari 1536. Den Haag, A.R.A., G.R.K., nr. 3539, f० 8vo.

(2) In 1532 werden, onder meer, volgende ambtenaren benoemd : Willem Goudt, ontvanger-generaal van Noord-Holland; Crispijn van Boschuysen, ontvanger-generaal in Zuid-Holland; Adriaan Stalpaert, rentmeester van Kenmerland-Friesland; Adolf Herdinck, rentmeester van Zeeland-Bewesterschelde ; Henri van den Werve, ontvangergeneraal van Zeeland-Beoosterschelde; Jehan Bertoul, Joris Grenet, Michel de Bouf- 
ger-generaal die de door Carondelet goedgekeurde taxaties aan deze functionarissen toestuurde ; hij zette aldus gans het inningsapparaat van de kerkelijke subsidie in beweging (1). Het was tenslotte ook de Raad van Financiën die de rekeningen van de ontvangers had aan te nemen, waarna de respectievelijke rekenkamers de eindcontrole doorvoerden $\left({ }^{2}\right)$. Op deze wijze geschiedde het gehele verloop van de kerkelijke belasting onder het beheer en de controle van 's keizers bestuurapparaat.

Hierin had Carondelet - zoals reeds gezegd - ook een zeer groot aandeel. De aanduiding van de gewestelijke commissarissen, de expeditie van de bullen in de bisdommen, de benoeming van de «taxateurs» en de collecteurs, de drukke correspondentie en de talrijke besprekingen brachten veel arbeid mede. Voor het schrijfwerk werd hij bijgestaan door zijn beschermeling Jan de Langhe, die later secretaris van de Geheime Raad werd ( ${ }^{3}$ ).

Aan de hand van de bewaarde rekeningen kan men - mits enige samentellingen - de werkelijke opbrengst van de kerkelijke subsidies nagaan. Uit de hieronder medegedeelde tabel kan men de opbrengst van de kerkelijke belasting van 1532 aflezen. Er moet evenwel een onderscheid gemaakt worden tussen de bruto-ontvangst

flers, Jehan Laloux, Conrard de Keyzer, Diedier Boisot waren allen ontvangers van het domein, respectievelijk te Arras, Bethune, Bapaume, Lens, Leuven en Mechelen. Ook Philips Vuesels, Janne Moys, Jehan Bax, Claes Bave en Jehan François, allen domeinontvangers, respectievelijk te Brussel, Antwerpen, 's-Hertogenbosch, Limburg en Luxemburg, werden tot collecteur aangesteld. Als voorbeelden van benoemingsbrieven van de collecteurs van het subsidie, zie bijlagen nrs. 1 en 3.

(1) Op 12 augustus 1534 bijvoorbeeld zond Jan Micault, ontvanger-generaal, aan Henri van den Werve, ridder en rentmeester van Beoosterschelde, de taxatie der geestelijke goederen in zijn kwartier, met last die zo spoedig mogelijk te innen. Zie R. FruIN, De rekeningen uit de Hollandse rekenkamer naar de Zeewwse overgebracht, Den Haag, 1909, p. 342 , nr. 730.

(2) Iedere rekening draagt de data van het «ten hove» dragen en van het afsluiten der rekening in de rekenkamer. De rekening van George De Rouck, ontvanger van Gent, Aalst, Dendermonde en de Vier Ambachten, werd op 21 april 1537 aan het Hof gebracht en op 28 april daaropvolgend te Rijsel afgehoord en gesloten; Brussel, A.R.A., Rekenk., nr. 16106, f० 1 et fo 28.

(3) In 1535 kreeg Jan De Langhe de belangrijke som van 240 pond « en despeschant soubz l'archévesque de Palerme, chief du privé conseil, le fait du subside ecclésiastique, accordé à l'empereur sur le clergé de pardeça ». Rijsel, A.D.N., B, nr. 2386, f॰ 242vº. 
en de geldsom die aan de ontvanger-generaal van Financiën werd overgemaakt. Deze laatste som werd rechtstreeks ten dienste gesteld van de doeleinden van $K$ arel $V$ en moet dus als de netto-opbrengst aangezien worden ( ${ }^{\mathbf{1}}$ ).

\begin{tabular}{|c|c|c|c|c|c|}
\hline Gewesten & Bruto- & Netto- & \multicolumn{3}{|c|}{ Archiefverwijzing } \\
\hline Brussel & 61.214 & 57.686 & Brussel, & Rek. & 15.762 \\
\hline Leuven & 30.202 & 26.600 & » & $"$ & 15.755 \\
\hline Antwerpen & 32.716 & 29.001 & » & $»$ & 15.768 \\
\hline $\begin{array}{l}\text { 's-Hertogenbosch } \\
\text { Limburg-Valken- }\end{array}$ & 22.655 & 20.858 & $»$ & $"$ & 15.776 \\
\hline burg-Overmaas & 16.446 & 12.614 & $»$ & " & 15.809 \\
\hline Luxemburg & 12.583 & 8.999 & $»$ & $»$ & 15.906 \\
\hline $\begin{array}{l}\text { Namen } \\
\text { Gent-Aalst-Vier }\end{array}$ & 10.984 & 9.900 & $»$ & " & 16.663 \\
\hline $\begin{array}{l}\text { Ambachten, enz. } \\
\text { Brugge-Vrije- }\end{array}$ & 41.374 & 37.700 & $»$ & $»$ & 16.106 \\
\hline Sluis & 22.734 & 21.220 & $»$ & $»$ & 16.107 \\
\hline $\begin{array}{l}\text { Mechelen } \\
\text { Ieper-Kortrijk- }\end{array}$ & 7.414 & 6.815 & $»$ & $»$ & 16.912 \\
\hline $\begin{array}{l}\text { Menen, enz. } \\
\text { Arras-Douai- }\end{array}$ & 9.533 & 8.500 & Rijsel, & Rek. B, & 6.880 \\
\hline Valenciennes & 58.430 & 50.816 & $»$ & $"$ & 16.798 \\
\hline Bethune & 6.278 & 5.846 & $»$ & $»$ & 16.799 \\
\hline Bapaume & 5.942 & 4.910 & " & " & 16.800 \\
\hline Lens & 4.967 & 4.084 & $»$ & " & 16.801 \\
\hline Noord-Holland & 23.731 & 20.162 & Den Haag, & Rek. & 3.538 \\
\hline $\begin{array}{l}\text { Zuid-Holland } \\
\text { Kenmerland- }\end{array}$ & 8.655 & 7.500 & $»$ & $»$ & 3.541 \\
\hline Friesland & 18.851 & 17.419 & " & " & $"$ \\
\hline $\begin{array}{l}\text { Voorne } \\
\text { Zeeland- }\end{array}$ & 2.903 & 2.700 & " & $"$ & $»$ \\
\hline $\begin{array}{l}\text { W. Schelde } \\
\text { Zeeland- }\end{array}$ & 7.558 & 5.236 & Middelburg, & Rek. & 450 \\
\hline O. Schelde & 2.920 & 2.150 & " & $»$ & $»$ \\
\hline Totaal & $408.090 \mathrm{lb}$. & $354.716 \mathrm{lb}$. & & & \\
\hline
\end{tabular}

(1) Bij het aangeven van de gewesten werd zo getrouw mogelijk de formulering van de rekeningen gevolgd opdat de vorser, die zich voor een bepaalde streek of kerkelijke 
$\mathrm{Nu}$ mag men zich terecht de vraag stellen wat er met de opbrengst van de kerkelijke subsidie is geschied.

Vooreerst dient opgemerkt dat het verschil tussen bruto- en nettoopbrengst $53.374 \mathrm{lb}$. bedraagt, hetgeen betekent dat ongeveer $13 \%$ van de totaalsom voor allerhande kosten werd besteed.

Onder deze laatste uitgaven zijn posten van verschillende aard. Eén der belangrijkste lasten waren de veelvuldige vacatiegelden die aan de provinciale commissarissen of aan de functionarissen van de Rekenkamers moesten uitbetaald worden $\left({ }^{1}\right)$. Ook de vergoedingen voor de geestelijken-dekens, die in hun woning de plaatselijke clerus samenriepen en een lijst van de beneficiën opstelden, liepen soms hoog op $\left({ }^{2}\right)$. Daarnaast had men de wedden van het inningspersoneel, zowel van de ontvangers als van hun klerken, alsmede de onkosten van de deurwaarders $\left({ }^{3}\right)$. Tevens is een zeer

instelling interesseert, gemakkelijk de desbetreffende bron zou kunnen terugvinden. Alle bedragen zijn uitgedrukt in ponden vlaams van 40 groten. De penningen en de schellingen werden in onze tabel niet opgenomen. De cijfers voor Namen kan men ook vinden bij D. BROuWERs, op. cit., pp. 83-87. De cijfers voor Luxemburg werden gedeeltelijk gepubliceerd door J. VANNERUs, Les biens et revenus du clergé Luxembourgeois au XVI• siecle, in Publications de la section historique de l'institut grand-ducal de Luxembourg, 1901, d. 49, pp. 254-267.

(1) In het kwartier van Leuven werd aan Filips Nigri 680 pond uitbetaald « voer zyn vacatiën gedaen int maken van der taxen». Aan Claes Van Arcle, rekenmeester van de Rekenkamer te Brussel werd, om dezelfde reden, 225 pond toegekend. Brussel, A.R.A., Rekenk., nr. 15755, fo 15. Aan Jacob de Jonge, rekenmeester in de Rekenkamer van Holland te Den Haag werd 250 pond « by den heeren van den financiën toegetaxeert voer zyn arbeyt ende moeyte gedaen in de zelve subsidie». Den Haag, A.R.A., G.R.K., nr. 3538, fo $20 \mathrm{v}^{\circ}$. Aan Gilles Cleerhage " auditeur van den Rekenkamere in Brabant ende commissaris up tstuck vanden geestelycken subsidiën in Zeelland " werden 196 pond toegekend. Middelburg, Rijksarchief, R.F., nr. 450, fo $10 \mathrm{v}^{\circ}$.

(2) Aldus bijvoorbeeld werden 14 pond toegekend aan «Jehan de Wilde, doyen de chrétienneté au quartier de Gand ... pour ses paines, journées, sallaires et vacations par lui faicts d'avoir adjourné tous les gens d'église de son doyennie pour bailler oultre la vraye valeur de leurs dignitéz et bénéfices touchant ledit subside, comme il appert par ordonnance signée et vérifiée de messeigneurs des finances... ». Brussel, A.R.A., Rekenk., nr. $16106, \mathrm{f}^{\circ} 19 \mathrm{v}^{\circ}$. Voor andere voorbeelden, ibidem, nr. 15.755, fo $15 \mathrm{v}^{\circ}$.

(3) George de Rouck, ontvanger van het subsidie in Oost-Vlaanderen, kreeg op 12 december 1536 de som van 550 pond «pour une foiz de gaiges» toegewezen, naast 112 schellingen « pour la grosse et minute de ce présent compte». Brussel, A.R.A., Rekenk.,

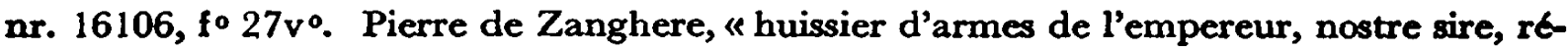


hoge som te vermelden voor de verschillende kwijtscheldingen die toegestaan werden. Sommige personen of instellingen konden hiertoe een geldige reden inroepen; anderen genoten van een gunstregeling dank zij een speciale tussenkomst van $K$ arel $V$ of van de landvoogdes Maria van Hongarije (1).

De netto-opbrengst werd echter integraal aan de ontvanger-generaal overgedragen. Uitzonderlijk kon een bepaalde som rechtstreeks aan de belanghebbende partij overgemaakt worden $\left({ }^{2}\right)$. Daarmede stelt zich hier het probleem van het werkelijk gebruik der gelden van het kerkelijk subsidie.

De gewone formule in de rekeningen luidt : «... en deniers payez au receveur général, pour convertir et employer au fait et conduite de son office» $\left(^{3}\right)$. Zeer dikwijls echter wordt een meer precieze bestemming opgegeven. De volgende omschrijving komt - in analoge termen - zeer veelvuldig voor: «A messire Jean Micault, la somme de $9000 \mathrm{lb}$. ... pour en faire payement à aulcuns marchans d'Anvers et entantmoings des trois cens cincquante six mil sept cens cincquante livres dudit pris, en quoy la royne et les seigneurs sont obligiéz envers eulx... ". Een weinig verder volgen overschrijvingen van zesduizend en drieduizend pond " pour la cause que dessus, mesmement pour en faire payement aux gens de guerre...» $\left(^{(4)}\right.$.

Bij een vorige studie werd aangetoond dat de staatsfinanciën in de jaren dertig van de zestiende eeuw dringend behoefte hadden aan een grondige reorganisatie. In 1531 beliep de openbare schuld trouwens meer dan vierhonderd duizend pond. Deze schuld was

sident en la ville de Bruges» kreeg 80 pond « pour pluisseurs voyaiges et vacations par lui faitz au recouvrement des deniers dudit subside, tout au long spécifiéz en ung quoyer de papier contenant la particularité des parties». Ibidem, nr. 16.107, f० 15.

(1) Een reeks attesten van vrijstellingen vindt men achteraan de rekening van OostVlaanderen. Brussel, A.R.A., Rekenk., nr. 16.107. Uiteraard vindt men telkens een reeks zulke posten opgenomen in het kapittel van de uitgaven der rekeningen.

(2) Zie bijvoorbeeld de toekenning van 27 pond aan de deurwaarder Anthoine Van Hille voor zijn driedubbele reis naar Antwerpen waar hij 17.000 pond aan Lazarus Tucker overhandigde. Brussel, A.R.A., Rek., nr. 16.106, f० 21.

(3) Ibidem, nr. 16.107, fo $11 \mathrm{vo}$.

(4) Ibidem, nr. 16.106, fo 14. 
hoofdzakelijk te wijten aan de voorgaande oorlog tegen Frankrijk die in 1529 met de vrede van Kamerijk besloten werd ( ${ }^{1}$ ). Ook in de daaropvolgende decennia bleef diezelfde toestand voortduren. De nieuwe oorlogen tegen Frankrijk brachten de begrotingen van de Nederlanden in een nog groter deficiet.

Uit de hierboven aangegeven citaten blijkt duidelijk dat de opbrengst van het kerkelijk subsidie van 1532 vooral aangewend werd voor het afbetalen van de meest drukkende leningen en lasten. Ook de rekeningen van de volgende kerkelijke belastingen kunnen analoge transacties prachtig illustreren $\left({ }^{2}\right)$.

De opbrengst van het subsidie van 1532, die aangewend moest worden in de strijd tegen de Turken, kreeg dus wel een enigszins gewijzigde bestemming. Ook in de zestiende eeuw moest men de " officiële » verklaringen zo ruim mogelijk kunnen interpreteren $\left({ }^{3}\right)$.

Hieronder tonen twee tabellen de inkomsten van het domein en de beden in de Nederlanden, respectievelijk tijdens de perioden 15311534 en 1535-1538. Ook deze sommen werden voor dezelfde doeleinden gebruikt. Deze cijfers laten overigens toe de relatieve waarde van de kerkelijke subsidies te kennen in het kader van de andere inkomsten van Karel $\mathrm{V}$ in de Nederlanden $\left({ }^{4}\right)$.

(1) Zie M. Baelde, art. cit., p. 15.

(2) Zie de bewaarde rekeningen, Brussel, A.R.A., Rek., nr. 15.740, fos 157-158;

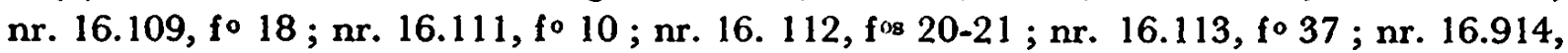
fo 14 ; enz.

(3) Men kan deze gang van zaken vergelijken met de argumentatie bij de aanvraag van een subsidie voor de citadel te Luik in 1651 waarbij de paus het Turkengevaar en de Duitse keizer eigenlijk het Franse gevaar voor ogen zag. Zie daarover J. Hoyoux, Une supplique de Maximilien-Henri de Bavière, prince-évêque de Liège au pape Innocent $X$, in Bulletin de l'Institut historique belge, 1962, d. 34, pp. 555-570.

(4) De cijfers steunen op twee vierjaarlijkse staten, bewaard te Brussel, A.R.A., Aud., $\mathrm{nr} .868, \mathrm{f}^{\circ \mathrm{s}} 4-10 \mathrm{v}^{\circ}$, en fos 105-106. Deze beide tabellen werden reeds medegedeeld in ons artikel, Financiële Politiek..., Tijdschrift voor Geschiedenis, 1963, d. 76, pp. 21-22. Verder vergelijkingsmateriaal vindt men bij A. Henne, Histoire du règne de Charles-Quint en Belgique, Brussel, 1859, d. 7, pp. 132-128. 
Periode 1531-1535:

\begin{tabular}{l|r|r}
\hline \multicolumn{1}{c|}{ Gewest. } & Domein. & Beden. \\
\cline { 3 - 3 } Brabant & 112.178 & 946.733 \\
Luxemburg-Limburg & 8.972 & 21.800 \\
Vlaanderen & 238.129 & 921.160 \\
Artesië & 34.636 & 239.494 \\
Henegouwen & 55.927 & 150.189 \\
Holland & 220.098 & 413.208 \\
Namen & 31.713 & 61.825 \\
\hline
\end{tabular}

Periode 1535-1538:

\begin{tabular}{l|r|r}
\hline \multicolumn{1}{c|}{ Gewest. } & Domein. & Beden. \\
Brabant & 181.645 & 1.624 .000 \\
Vlaanderen & 68.717 & 1.350 .000 \\
Doornik & 24.000 & 27.600 \\
Artesië & 41.624 & 257.851 \\
Henegouwen & 147.073 & 307.000 \\
Holland-De Briel & 86.420 & 564.700 \\
Zeeland & 78.283 & 211.191 \\
Namen & 46.290 & 40.000 \\
\hline
\end{tabular}

$\mathrm{Na}$ dit alles mag men wel besluiten dat het kerkelijk subsidie van 1532 een waar succes is geweest voor Karel V en de landvoogdes Maria van Hongarije. Dit prachtig resultaat zal trouwens zeer aanstekelijk werken en nieuwe kerkelijke subsidies werden dan ook nog herhaaldelijk in de Nederlanden uitgevaardigd.

\section{$*^{*} *$}

De eerstvolgende kerkelijke belasting werd in 1542 op 19 april door paus Paulus III toegestaan ( ${ }^{1}$ ). Als algemeen executor werd nu niet Jan Carondelet maar wel Filips Nigri, lid van de Raad van

(1) Zie J. LAEnen, Les archives de l'élat à Vienne au point de vute de l'histoire de Belgique, Brussel, 1924, p. 224. Enkele gegevens verstrekt ook A. HenNe, op. cit., d. 8, p. 48. 
State en kanselier van de Orde van het Gulden Vlies, aangeduid. Eerstgenoemde had in 1540 ontslag genomen uit alle centrale bestuursorganen en hij verlangde blijkbaar geen rol meer te spelen in het publieke leven. Nochtans werd hij niet volledig afzijdig gehouden van de nieuwe kerkelijke subsidie. Volgens een instructie van 10 december 1541 werd Adolf van Pamele, raadsheer van de Geheime Raad en zoon van de baljuw van de proosdij van Sint Donaas, naar Carondelet, de proost van het Sint Donaaskapittel, gestuurd. Deze laatste, als hoogste kerkelijke hoogwaardigheidsbekleder, kreeg de opdracht de pauselijke bul in de bisdommen bekend te maken. Van de verdere activiteiten betreffende de uitvoering werd hij echter volledig ontslagen $\left({ }^{1}\right)$. Deze taak werd door Filips Nigri waargenomen, die dus de volledige verantwoordelijkheid van de executie op zich kreeg.

Dit subsidie volgde een analoge weg als de voorgaande. Een grotere faciliteit echter was het uitschakelen van de taxatiebezigheden. In 1542 nam men heel eenvoudig de kohieren over van 1532 ; deze werden nu enkel nog door Nigri goedgekeurd en ondertekend ( $\left.{ }^{2}\right)$.

Toch had Nigri, een bekwaam onderhandelaar, met veel meer moeilijkheden af te rekenen dan zijn voorganger Carondelet. In een brief uit Brussel, 25 augustus 1542, schrijft de landvoogdes Maria aan Keizer Karel V deze zeer merkwaardige gegevens : «... Et pour advertir Vostre $\mathrm{Ma}^{\text {té }}$ de ce que on pourra avoir des demy fruitz des biens ecclésiastiques comme désirez par voz lettres du $\mathrm{X}^{\mathrm{e}}$ de juing, $\mathrm{j}^{\prime}$ ay entendu que la dernière fois lesditz fruitz montraient à plus de IIIIc $M$ carolus mais ne monteront présentement à beaucoup près si hault, à cause du grant dommaige que les pays ont souffert par ceste guerre, par laquelle la moitié du plat pays de Brabant est pillé et ne scaura riens payer ; les pays d'Arthois et Luxembourg sont entièrement destruitz et repaieront les gens d'église peu ou riens; le pays de Haynnau sur les frontières de France est désert et non habité avecq ce que les prélatz dudit Brabant sont excuséz de ceste contribution par la promesse à eulx faicte

(1) Volgens de instructie, bewaard te Wenen, H.H.S.A., P.A., nr. 38, fo 4.

(2) Een levensschets van Nigri vindt men in Biographie Nationale, d. 15, p. 734. Als voorbeeld van zijn taxatietaak, zie Brussel, A.R.A., Rekenk., nr. 15.740, fo 3 . 
en accordant l'ayde de VI ans. J'ai fait tout debvoir possible de lever lesditz demy fruitz en deux années et quatre termes et que le terme de St. Jehan passé pust estre le premier, pour moy ayder en ceste toute urgente nécessité, mais je n'en ay sceu obtenir le consentement et sera le premier terme à Noël prochain. J'ay sur les obligations des receveurs fait anticiper tout ce que j'ay peu desdits demi fruitz, car sans ceste anticipation n'avoye riens pour lever gens de guerre à cause que les aydes extraordinaires accordées sont condicionèles et à termes, dont encoires on a bien peu receu, de sorte que si je n'eusse eu la commodité desdits demy fruitz, voz pays eussent esté perdue devant que on eust peu lever gens de guerre» (1).

Aanvankelijk was dus voorzien de belasting in vier termen op te halen, namelijk op St. Jan en Kerstmis 1542 en op dezelfde data in 1543. Naderhand werd de eerste vervaldatum verschoven tot Kerstmis 1542. De reguliere geestelijkheid van Brabant werd volledig van dit subsidie vrijgesteld daar haar aandeel in de zesjarige bede van 15401.200 .000 pond bedroeg. In 1542 sprak men echter niet van vrijstelling maar wel van opschorting « afin de point exciter murmurations entre les autres gens d'église contre lesditz prélatz et se doibt icelle surcéance desdits prélatz entendre pour plaine grace » $\left({ }^{2}\right)$.

Hierbij dient aangestipt dat de prelaten niet werden vrijgesteld voor hun goederen buiten Brabant gelegen, wat aanleiding heeft gegeven tot vele misverstanden, moeilijkheden en oppositie $\left({ }^{3}\right)$. Daarnaast bracht de kwestie van de tiende penning van 1543 veel complicaties teweeg $\left(^{4}\right)$. Ook Doornik had in 1537 vrijstelling verkregen $\left(^{5}\right)$.

(1) Brussel, A.R.A., Aud., nr. 53, fo 251.

(2) Ibidem, Rekenk., nr. 15.740, fo 73.

(3) Zie de gedeeltelijke publikatie door Gorissen, art. cit., pp. 115-116. Cfr. ook A.R.A., Rekenk., nr. 15.740 , fo 73 en fo 160.

(4) Een passage uit de rekening van Nicolas Nicolai, ontvanger van het subsidie in Brabant, luidt : « ... attendu que la présente recepte dudit subside a esté beaucop plus pénible et facheuse que celle de l'an XXXIII, à cause de la ruse que l'on a eu pour rabastre et deffalquer à bons ecclésiastiques et bénéficiés le $\mathrm{X}^{\mathrm{e}}$ denier par eulx payé l'an XLIII et de chascun en particulier découvrer quictance et déclaration pertinente...». Ibidem, fo 163. Voor Vlaanderen, ibidem, nr. 16.109, fo 22vo.

(5) Zie de akte van 23 april 1537, Brussel, A.R.A., Aud., nr. 776/1. 
De afwezigheid van de geestelijkheid van Holland, Kenmerland, Friesland en Voorne is wellicht ook uit te leggen door een speciale subsidie eveneens in 1537 aan $\mathrm{Karel} V$ toegestaan, terwijl de drie Staten van Artesië in februari 1542 nog 30.000 pond gestemd hadden $\left(^{1}\right)$.

De hiernavolgende tabel geeft dus de bruto- en de netto-opbrengst van de kerkelijke belasting van $1542\left({ }^{2}\right)$.

\begin{tabular}{|c|c|c|c|c|c|}
\hline \multirow{2}{*}{$\begin{array}{l}\text { Gewesten. } \\
\text { Brussel }\end{array}$} & \multirow{2}{*}{$\begin{array}{c}\begin{array}{c}\text { Bruto- } \\
\text { Ontvangst. }\end{array} \\
60.116\end{array}$} & \multirow{2}{*}{$\begin{array}{c}\begin{array}{c}\text { Netto- } \\
\text { Ontvangst. }\end{array} \\
-\end{array}$} & \multicolumn{3}{|c|}{ Archiefverwijzing. } \\
\hline & & & Brussel, & Rek. & 15.740 \\
\hline Leuven & 29.891 & - & $»$ & $»$ & $»$ \\
\hline Antwerpen & 31.840 & - & $»$ & $»$ & $»$ \\
\hline 's-Hertogenbosch & 23.018 & - & $"$ & $»$ & $»$ \\
\hline totaal Brabant & 144.867 & 89.446 & $»$ & $»$ & $»$ \\
\hline $\begin{array}{l}\text { Limburg-Valken- } \\
\text { burg-Overmaas }\end{array}$ & 16.446 & 6.644 & » & $»$ & 15.809 \\
\hline $\begin{array}{l}\text { Namen } \\
\text { Gent-Aalst-Vier }\end{array}$ & 10.984 & 9.602 & $»$ & $"$ & 16.675 \\
\hline $\begin{array}{l}\text { Ambachten, enz. } \\
\text { Ieper-Kortrijk }\end{array}$ & 41.434 & 31.005 & $»$ & " & 16.109 \\
\hline $\begin{array}{l}\text { en Rijsel } \\
\text { Zeeland- }\end{array}$ & 26.971 & 24.498 & Rijsel, & $\mathrm{B}$, & 6.905 \\
\hline $\begin{array}{l}\text { W. Schelde } \\
\text { Zeeland- }\end{array}$ & 7.558 & 5.000 & Middelburg, & Rek. & 453 \\
\hline O. Schelde & 2.920 & 2.000 & $»$ & $\gg$ & $»$ \\
\hline Totaal & $251.180 \mathrm{lb}$. & $168.195 \mathrm{lb}$. & & & \\
\hline
\end{tabular}

(1) Voor eerstgenoemden, zie de vrijstelling van Karel V, Brugge, 25 augustus 1537. Den Haag, A.R.A., G.R.K., nr. 3.542. Voor Artesië zie de brief van de Staten, Arras. 24 juli 1542. Brussel, A.R.A., Aud., nr. 1.643.

(2) De bedragen zijn opnieuw in ponden vlaams van 40 groten uitgedrukt. De afwezigheid van verscheidene gewesten is te wijten ofwel aan vrijstellingen ofwel aan het ontbreken van de rekeningen. Slechts voor het subsidie van 1532 is er praktisch een volledig bewaarde dokumentatie. Ook de rekeningen van de subsidies vóór dit jaartal zijn niet bewaard gebleven. Zie daarover H. Nelis, Inventaire des registres des Chambres des Comptes, Brussel, 1931, d. 6, p. 229. 
De minder hoge opbrengst van het kerkelijk subsidie van 1542 kwam de staatsfinanciën niettemin zeer van pas. Uit een schrijven van de landvoogdes Maria van Hongarije aan Karel V, Namen, 24 september 1542, blijkt dat zij moeilijk geld kon vinden voor het ontslaan van de oorlogstroepen en voor het onderhoud van de grensgarnizoenen « en tant que les aydes ordinaires sont anticipés pour l'an XLIII et XLIIII comme est aussy tout ce que doibt venir du subside ecclésiastique et que j'ay despendu deux aydes extraordinaires accordez par tous les estatz des pays à lever promptement par finances et vendition des rentes, impostz et autrement ... " ( $\left.{ }^{1}\right)$. Ook hier blijkt eens te meer dat de opgebrachte gelden direkt dienden voor de oorlog tegen Frankrijk ( $\left.{ }^{2}\right)$.

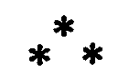

De blijvende vraag naar geldmiddelen in de Nederlanden bracht reeds in 1546 een nieuwe kerkelijke belasting. Rekening houdend met het feit dat de voorgaande slechts in 1544 volledig geind was, moet men die derde aanslag als een zeer vlugge opvolgster van deze van 1542 beschouwen.

Vooraleer de bul werd uitgevaardigd hadden paus Paulus III en de raadsheer Granvelle op 26 juni de modaliteiten van de nieuwe belasting reeds vastgelegd ${ }^{(3)}$. Het kerkelijk subsidie van 1546 vertoont een grote gelijkenis met de voorgaande belastingen van 1532 en 1542. Het was opnieuw Filips Nigri die als algemeen executor werd aangesteld (4). Als taxatie werd eveneens de aanslag

(1) De geciteerde tekst vindt men te Brussel, A.R.A., Aud., nr. 53, fo 299 vo.

(2) Op 18 september 1542 schreef de landvoogdes Maria aan Karel V: «... comme j'ay entendu [que] les estatz de l'empire ne vouldront avoir regart à la guerre de France, que seroit chose par trop déraisonnable, d'aultant plus que la résistance contre France peult estre attribué à la résistance contre le Turcq pour les intelligences que le roy de France a avecq ledit Turcq et que la guerre présente contre voz pays de pardecha ne se fait à autre occasion que pour favoriser au Turcq et distraire voz forches». Ibidem, nr. 53 , fo 291 .

(3) Zie ook A. HenNe, op. cit., d. 8, pp. 281-282.

(4) Naast vrijstellingen van 50 en 238 pond kreeg Nigri nog 30 pond toegewezen op 25 januari 1547 « pour les longs et agréables services qu'il a faict à Sa $\mathrm{Ma}^{\text {té }}$ et fait encoires journellement, mesmement pour le recompenser des paines et labeurs qu'il a prins à 
van 1532 genomen; hierbij moet men echter rekening houden met de telkens verschillende gunstregelingen $\left(^{1}\right)$.

De nieuwe belasting bracht begrijpelijkerwijze veel misnoegen in de betrokken kringen. De landvoogdes Maria schreef op 25 september 1546 aan Karel V als volgt : «... Et comme les gens d'église trouveront dur de rechief donner les demy fruitz, veu qu'il n'y a que deux ans qu'ilz ont payé le reste des derniers demy fruitz, avecq ce que depuis l'an XLIIII ont payé deux foiz le $\mathrm{X}^{\mathrm{m}}$ e avecq les gens laycs, et que plusieurs d'eux sont esté fort adommaigés par les dernières guerres, j'avoye advisé, par le conseil des bons personaiges estans lez moy, pour parvenir à l'exécution desditz demy fruits sans grande clameur et murmuration desdits gens d'église, qui peulvent bien mal faire vers le populaire quant ilz vueillent, de consentir qu'ilz peuvent payer en deux ans et quatre termes, dont Noël prochain seroit le premier...» $\left(^{2}\right)$.

Het subsidie van 1546 moest dus in vier termen afbetaald worden, namelijk op Kerstmis 1564, op St. Jan en Kerstmis 1547 en op St. Jan 1548. De prelaten van Brabant werden opnieuw vrijgesteld, maar dit bracht niettemin vele zorgen mede $\left({ }^{3}\right)$.

raison de sa charge et commissairie du nouveau subside...» Brussel, A.R.A., Rekenk., nr. 15.743 , fo 79 .

(1) Claude Carondelet, proost van St. Donaas te Brugge en neef van de in 1544 overleden Jan Carondelet, aartsbisschop van Palermo, kreeg op 19 april 1547 een gratie en vrijstelling van 778 pond. Brussel, ibidem, nr. 16.111, fo 12.

(2) Brussel, A.R.A., Aud., nr. 58, to 65v०.

(3) In november 1545 hadden de prelaten van Brabant medegestemd met de andere Staten van Brabant voor een driejaarlijkse bede van 250.000 pond per jaar. Daardoor werden zij van toekomstige subsidies vrijgesteld. Dit werd bevestigd door een akte van 19 januari 1548 waarbij uitzondering gemaakt werd voor de goederen buiten Brabant gelegen. Zie Brussel, A.R.A., Rekenk., nr. 15.743, fo 71. In de reeds vermelde brief van 25 september 1546 schrijft de landvoogdes Maria daarenboven : « Monseigneur, j'ai receu les bulles des demy fruitz, esquelles j'ai trouvé une clause par laquelle l'on exempte les prélatz de Brabant desditz demy fruitz soubz couleur qu'ilz contribuent avec les gens séculiers ... il est à craindre que ladite clause pourra donner grant empeschement et troubler entièrement la levée desditz demy fruitz, car aultres gens d'église, voyans ... ladite clause, vouldront maintenir que par la mesme raison ilz ne doibvent riens donner ou payer pour les biens pour lesquelz ilz contribuent avecq les gens lays, mais seulement pour les biens qui sont francqz d'aydes; en ce faisant, non seulement seront lesditz demy fruitz grandement diminuéz mais aussy conviendroit esclaircir et distinguer quels biens 
De hiernavolgende tabel geeft de opbrengst van dit subsidie ( ${ }^{1}$ ).

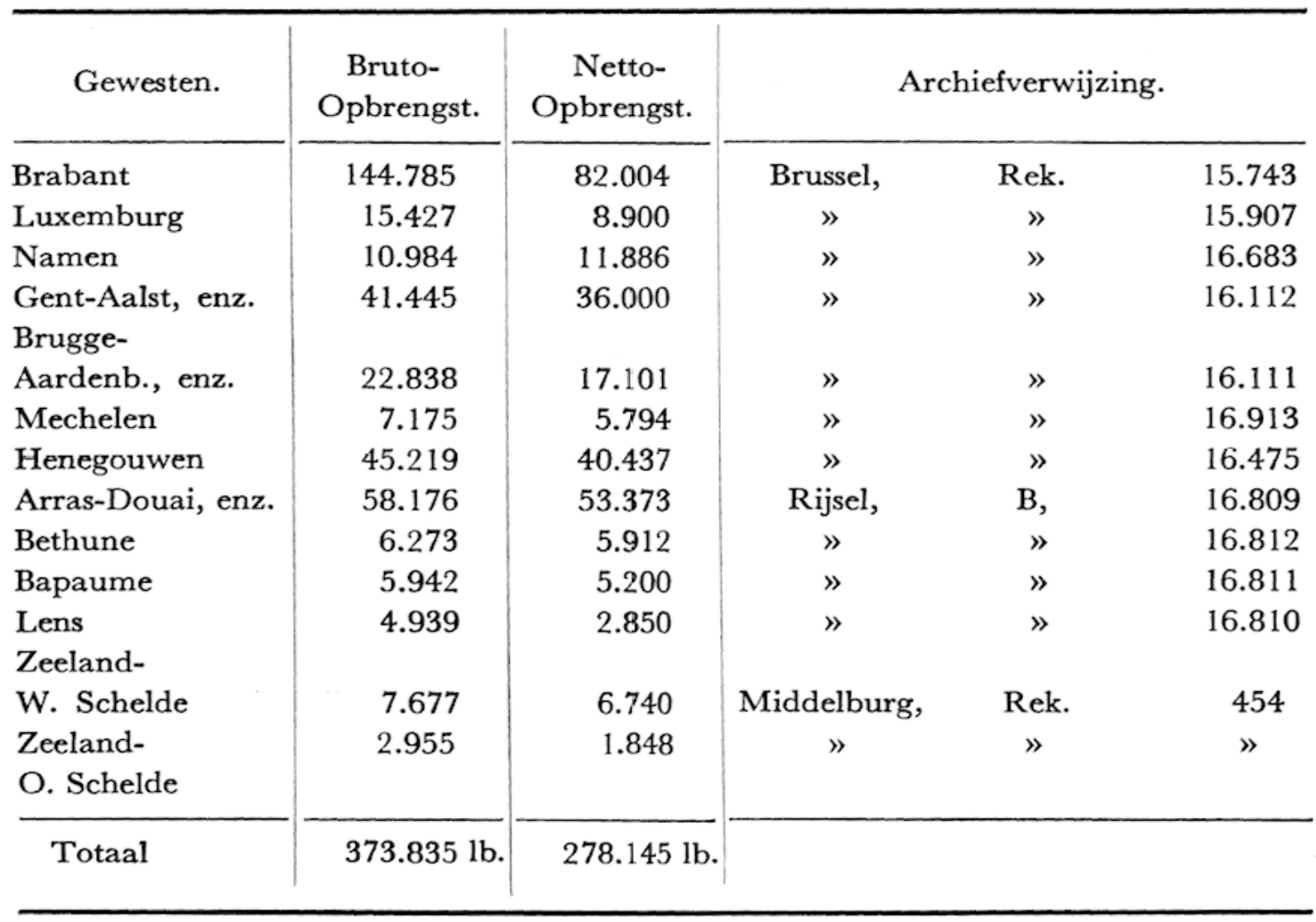

Reeds in 1552 werd opnieuw een kerkelijk subsidie gevraagd. Op 27 juli van dit jaar gaf paus Julius III aan Keizer Karel V de toelating om in twee beurten een kerkelijke belasting te heffen « aux gens d'église de tous les diocèses consistans en nosditz pays de par deça..." ( $\left.{ }^{2}\right)$. De kerkelijke belasting kwam zo vlug na de voorgaande, omwille van de oorlog tegen Frans I.

sont franqz d'aydes et quelz non, que seroit chose bien difficille et de grande coustaige et en quoy les gens d'Eglise pourroient faire pluiseurs abus... \$. Idem., Aud., nr. 58, fo $65 v^{\circ}$.

(1) De respectievelijke opbrengsten van Leuven, Brussel, Antwerpen en 's-Hertogenbosch bedroegen $29.841,69.519,31.653$ en 22.615 pond. Daarnaast is nog een verhoging van 655 pond bij te rekenen. Brussel, A.R.A., Rekenk., nr. 15.743, fos 15, 37, 51, 68vo en 70v'. Zie ook noot 2, p. 1258.

(2) Zie deze inlichtingen in de benoemingsbrief van Jan Claiszone, ontvanger-generaal van West-Vlaanderen, als gewestelijk collecteur van dit subsidie. Brussel, ibidem, nr. 16.113 , fo 1 . 
Als algemeen executor en commissaris werd nu Antoon Perrenot, bisschop van Arras, de latere kardinaal Granvelle, aangesteld. Perrenot was de eerste raadsheer en zegelbewaarder van Karel V, dit in opvolging van zijn vader Niklaas, die in 1550 overleden was ( ${ }^{1}$ ).

De eerste vervaldag van het kerkelijk subsidie was voorzien op het einde van het jaar 1552 maar werd nadien verschoven tot Pasen 1553, zodat de laatste vervaldag eveneens naar Pasen 1554 verwezen werd $\left({ }^{2}\right)$. De prelaten van Brabant werden opnieuw vrijgesteld doordat zij bijdroegen in de zesjarige bede van 1.500 .000 pond die in 1548 een aanvang had genomen ( ${ }^{3}$ ).

In de hiernavolgende tabel kan men de opbrengst van het subsidie van 1552 aflezen $\left({ }^{4}\right)$.

\begin{tabular}{|c|c|c|c|c|c|}
\hline \multirow{2}{*}{$\frac{\text { Gewesten. }}{\text { Brabant }}$} & \multirow{2}{*}{$\begin{array}{c}\begin{array}{c}\text { Bruto- } \\
\text { Opbrengst. }\end{array} \\
141.188\end{array}$} & \multirow{3}{*}{$\begin{array}{c}\begin{array}{c}\text { Netto- } \\
\text { Opbrengst. }\end{array} \\
71.625\end{array}$} & \multicolumn{3}{|c|}{ Archiefverwijzing. } \\
\hline & & & Brussel, & Rek. & 15.764 \\
\hline Limburg- & & & & & \\
\hline s'-Hertogenrade & 16.446 & 10.000 & $»$ & $»$ & 15.809 \\
\hline Namen & 10.984 & 7.631 & $»$ & " & 16.691 \\
\hline Luxemburg & 11.474 & 8.900 & $»$ & $»$ & 15.907 \\
\hline \multicolumn{6}{|l|}{ Brugge-Vrije- } \\
\hline Kortrijk & 32.579 & 25.600 & $»$ & $»$ & 16.113 \\
\hline Mechelen & 7.175 & 4.919 & $»$ & $»$ & 16.914 \\
\hline \multicolumn{6}{|l|}{ Zeeland- } \\
\hline O. Schelde & 2.920 & 1.497 & Middelburg, & $»$ & 454 \\
\hline Totaal & $221.766 \mathrm{lb}$. & $130.172 \mathrm{lb}$. & & & \\
\hline
\end{tabular}

Het is bekend dat de oorlog tegen Frankrijk ontzaglijke lasten met zich heeft medegebracht. Alle hulpmiddelen werden aange-

(1) Voor een levensschets, zie Biographie Nationale, d. 8, p. 185. Zie ook M. VAN DuRME, Antoon Perrenot, bisschop van Atrecht, Kardinaal van Granvelle, minister van Karel $V$ en van Filips II (1517-1586), Brussel, 1953.

(2) Zie Brussel, A.R.A., Rekenk., nr. 16.113, fo 1.

(3) Ibidem, nr. 15.746, f० $67 \mathrm{v}^{\circ}$.

(4) De bedragen zijn opnieuw in ponden vlaams van 40 groten uitgedrukt. Voor de afwezige gewesten, zie noot 2, p. 1258. 
boord en alle financieringskansen benut. De kerkelijke subsidie van 1552, die het minst van alle kerkelijke subsidies opbracht, heeft een kleine maar niettemin een zeer efficiënte hulp kunnen bieden in het oorlogsgebeuren. Reeds op 10 mei 1553 kon Jan Claiszone, ontvanger-generaal van West-Vlaanderen en belast met de collectie in het bisdom Doornik, een som van 11.100 pond aan de ontvanger-generaal van Financiën overdragen « pour furnir au payement des gensdarmes des ordonnances et piétons levez de crue pour la deffence et préservation de ces pays durant la présente guerre..." $\left({ }^{1}\right)$. Op 18 maart 1555 had hij in totaal een som van 25.600 pond gestort $\left({ }^{2}\right)$.

Het is overduidelijk dat men met de kerkelijke subsidies op een tamelijk vlugge manier aan kontant geld kwam en dat de voorziene op te halen sommen tevens als borg gesteld werden voor het aangaan en het aflossen van de leningen.

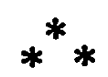

In deze studie werden enkel de kerkelijke subsidies gedurende de periode 1532-1555 bestudeerd. Deze belastingen waren overigens noch de eerste noch de enige kerkelijke aanslagen tijdens de regering van Karel V.

Reeds op 13 september 1515 verkreeg Karel V van paus Leo X het recht om een tiende te heffen op de inkomsten van de geestelijkheid in de Nederlanden ter verbetering van de dijken $\left({ }^{3}\right)$. In 1529 werd eveneens beslist gelden op te halen voor een kruistocht tegen de Turken $\left({ }^{4}\right)$. Ook de tiendeheffingen in de jaren 1530-1555 werden hier niet bestudeerd.

Naast een chronologische beperking is er ook nog een territoriale begrenzing. Tijdens de regering van Karel $\mathrm{V}$ werden ker-

(1) Brussel, A.R.A., Rekenk., nr. 16.113, fo 37.

(2) Ibidem, fo $37 v^{\circ}$.

(3) Voor deze heffing raadplege men F. RemY, Les grandes indulgences pontificales au Pays-Bas a la fin du Moyen-Age (1300-1531), Leuven, 1928, p. 185.

(4) Zie eveneens F. Remy, op. cit., p. 193. Zie ook L. Gilliodts-Van Severen, La croisade de 1530, ordonnée par Charles-Quint, in Bulletin de la Commission royale d'histoire, $4^{\mathrm{e}}$ reeks, d. 16,1889, pp. 262-263. 
kelijke subsidies in gans het Rijk uitgevaardigd. In Spanje bijvoorbeeld werden de ongeveer gelijktijdig uitgevaardigde subsidies bestudeerd door $\mathbf{R}$. Carande ( $\left.{ }^{1}\right)$. Ook voor het prinsbisdom Luik zijn enkele gegevens beschikbaar $\left({ }^{2}\right)$.

$\mathrm{Na}$ dit alles mag men niettemin verklaren dat de hier bestudeerde subsidies de belangrijkste kerkelijke belastingen waren in de Nederlanden tijdens de regeringsjaren van Keizer Karel V. Het succes van deze belastingen was mede te danken aan de energieke landvoogdes Maria van Hongarije en aan het degelijk bestuursapparaat die de behoudsgezinde gesteldheid van de bevoorrechte geestelijke stand hebben kunnen overwinnen $\left({ }^{3}\right)$.

De dokumenten, hierna in bijlage medegedeeld, dienen slechts om onze uiteenzetting concreter toe te lichten.

\author{
M. BAelde. \\ Aangesteld navorser N.F.W.O.
}

\title{
BIJLAGEN
}

$\mathbf{I}$

Jan Carondelet, aartsbisschop van Palermo, benoemt George De Rouck tot collecteur van het kerkelijk subsidie in Gent, Oudburg, Aalst, Audenaarde, Dendermonde en de Vier Ambachten.

Brussel, 23 oktober 1533 ; kopie.

Brussel, A.R.A., Rekenk., nr. 16.106.

Jehan Carondelet, archevesque de Palerme, chief du conseil privé de l'empereur nostre sire, commissaire exécuteur et collecteur général ordonné par nostre saint père le pape au fait et exécution du subside ecclésiasticque, ac-

(1) Zie R. Carande, Carlos $V$ y sus banqueros, Madrid, 1949. Voor de subsidies van $1532,1536,1542,1548$ en 1552, zie aldaar, pp. 474-486; voor de subsidies van 1519 en 1523, zie p. 466 en p. 469 . Over het subsidie van 28 augustus 1532 schrijft deze auteur : « De ningún otro súbsidio del reinado reúne Simancas tanta información ». Idem, p. 474. Voor het subsidie van 1532 in de Nederlanden kan men dit gerust onderschrijven.

(2) Zie de studie van L. E. HaLkIn, Le Cardinal de la Marck, prince-évéque de Liege (1505-1538), Luik, 1930, pp. 209-210.

(3) Het zou hier uiteraard zeer interessant zijn om de houding en de reacties van de verschillende geestelijke instellingen tot in de details te bestuderen. 
cordé par Sa Sainteté audit seigneur empereur sur le clergié de ses pays patrimoniaulx et autres de pardeça, à tous ceulx qui ces présentes lettres verront, salut. Savoir faisons que désirans de tout nostre povoir obéyr au commandement de nostredict saint père au fait de ladite exécution et pour la bonne cognoissance que avons de la personne de George de Rouck, nous confians de ses loyaulté et bonne diligence, eu préalablement sur ce l'advis des chiefs, trésorier et commis sur le faict des demaine et finances dudit seigneur empereur, avons commis et ordonné, commettons et ordonnons par ces présentes icelluy George de Rouc pour recouvrer et cueillir les deniers procédans dudit subside sur les gens d'église et clergié des diocèses estans et resortissans es villes et quartiers de Gand,Viesbourg, Alost, Audenarde,Tenremonde, Waes et quatre mestiers, leurs appartenances et appendences, de bailler ses lectres de recepte et quictance à ceulx qu'il appartiendra, lesquelz leur vauldront acquict et pour telz, si avant que besoing soit, les avons auctorisé et auctorisons par cestes de constraindre ou faire constraindre tous ceulx et celles qu'il appartiendra à furnir et payer selon les taux et assièctes qui en seront par nous faictes, et au surplus de faire bien et deuement tout ce que bon et léal receveur dessusdit peut et doit faire, aux gaiges que luy seront cy après ordonnez, pourveu que ledict George de Rouck sera tenu de soy bien et deuement acquicter en icelle recepte et entremise, et d'en rendre bon et léal compte et reliqua et avecq ce de bailler bonne scure et souffissante caucion et faire le serment à ce due et pertinent es mains des gens des comptes à Lille . Si requerons à ung chacun et ceulx qu'il appartient que ledit serement faict et caution baillee par ledit George de Rouck tel et ainsi que dit est, vous le faictes souffrer et laissez joyr et user dudit estat de receveur cessans tous contreditz et empeschemens. En tesmoings de ce nous avons faict mectre nostre scel armoyé de noz armes à ces présentes.

Donné en la ville de Bruxelles, le XXIIIe jour d'octobre, l'an mil cincq cens trente trois.

Sur le reply est escript : Par Monseigneur révérendissime de Palerme, commissaire etc. Soubssigné : Verreycken.

Et sur le dos estoit escript : Aujourdhuy, XIIII e jour de novembre mil $\mathrm{XV}^{\mathrm{c}}$ trente trois, George de Rouck, dénommé au blanc de ces présentes, a faict le serment pertinent et baillié caution de l'office de commis à recouvrer et cueiller les deniers procédans du subside ecclésiastique accordé par nostre saint père le pape à l'empereur sur les gens d'église et clergié des diocèses estans et resortissans es villes et quartiers de Gand Viesbourg, Allost, Audenarde, Tenremonde, Waes et quatre mestiers, leurs appertenances et appendences dont dudit blanc est faicte mencion es mains de messeigneurs des comptes à Lille. Soubsscript, moy présent, signé : Bosquiel.

Collationné aux lettres originalles par moy (getekend): Thilleman. 
Instructie voor Jacques de Rouck, deken van Nijvel, raadsheer in de Grote Raad van Mechelen, betreffende de propositie van het kerkelijk subsidie aan de geestelijkheid van het bisdom Kamerijk.

Binche, 8 januari 1542 ; minuut.

Wenen, H.H.S.A., P.A., nr. 38, fos. 40-43.

Instruction pour mestre Jacques de Roeck, doyen de Nyvelle, conseiller et maistre des requestes ordinaire de l'empereur en son grand conseil à Malines, de ce qu'il aura à besoingner à Mons où la royne régente l'envoye vers le clergié de Cambray qui doibt illecq estre rassemblé au $\mathrm{XX}^{\mathrm{e}}$ de ce présent mois de janvier.

Premiers, à son arrivee illecq présentera ses lettres de crédence à ceulx dudit clergié et icelles leutes déclairera estre illecq venu de la part de Sa $\mathrm{Ma}^{\text {té }}$ pour leur remonstrer comment l'empereur depuis qu'il est venu seignourie et a prins possessions de ses réaulmes et pays, a tousiours contendu de tout son povoir à tenir sesditz pays et subgectz en paix et tranquillité avec les princes chrestiens ses voisins et autres, afin d'avoir meilleure commodité de povoir entendre à l'extirpation des erreurs et maulvaises sectes qui sont esté semees et dispersees par héréticques en l'église cristienne. Et afin aussi d'avoir occasion et opportunité de convertir ses forces au reboutement du Turcq, ennemi de nostre sainte foy catholique, lequel a faict jusques ores et fait encoires tous les jours grandz effors pour ruiner la christienneté et petit à petit la subiugier et mettre en sa tirannicque subièction et obéyssance.

Dont depuis quelques annees les démonstrations évidentes se sont veues à Constantinoble, Rodes et dernièrement en Hongrie qui est chose lamentable et pitoyable.

Laquelle Hongrie il eust désia du tout subjugié ne fust que $\mathrm{Sa} \mathrm{Ma}^{\text {té }}$ y résista en personne, ayant une belle et puissante armee de gens de cheval et de piet avec grand nombre d'artillerie, lors que ledit Turcq descenda pour assiéger Vyenne en Austrice, lequel $\mathrm{Sa} \mathrm{Ma}{ }^{\text {té }}$ contraindit honteusement soy retirer non sans grande perte de ses gens.

Cc néantmoins l'armee dernièrement passee est de rechief retourné pour parachever sa mauldicte emprinse et du tout occuper ladicte Hongrie, à quoy aussi n'a sceu parvenir obstant que Sadite Maté avoit envoyé à ses propres coustz et despens au secours du Roy des Romains son frère, grand nombre de gens de cheval et de piet.

Et estoit apparent que ledit Turcq fust venu à chief de son intencion veu la petitte résistence qu'il $y$ avoit pour les guerres et affections passees soustenues par les hongrois et aussi les divisions d'Allemagne, ne feust ladite ayde et secours fait par Sadite $\mathbf{M a}^{\text {té }}$.

Davantaige ceste annee Sadite $\mathrm{Ma}$ té, après avoir esté longue espace de temps en Allemagne pour appaisier les sectes et factions y estans, et ayant 
fait son debvoir comme prince catholique de réduire les desvoyez au bon chemin, continuant son bon vouloir et louable intencion aussi pour divertir les forces dudit ennemie et Turcq et le débiliter, a encoires levé une belle et puissante armee bien esquippée de navires, artillerie et toute autre munition de guerre, avecq laquelle, es mois d'octobre et de novembre derniers, il a faict voille et s'est tirée vers la ville Dargel en Numidie, possessée par ledit Turcq dont Barberousse est capitaine, en laquelle expédition Sadite $\mathbf{M a}^{\text {té }}$ n'a espargnié sa personne ne ses biens. Ains y a esposé sa vie en grand péril et dangier, la postposant au .bien de la république christienne. Et est vraisamblable que son voyaige n'eust esté sans fruit si les tempestes des vens et de la mer n'eussent empeschié les vivres sans lesquels comme est notoire l'armee ne se povoit entretenir. Pardessus ce est en fresche mémoire ce que Sadite Maté a fait en Thunes victorieusement et à force d'armes, débattant ledict Turcq et ses gens qu'il y avoit et restituant le vray roy lequel s'est rendu tributaire à $\mathrm{Sa} \mathrm{Ma}^{\text {té }}$.

Tous lesquelz vertueux actes avantditz et les autres bons exploitz que Sa-

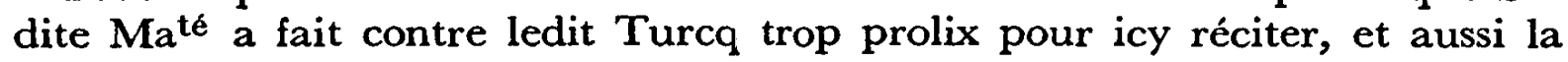
grande et incrédibile despence qu'elle a supporté es guerres que les Mores continuellement luy ont faict et font, ont esmut nostre sainct père le pape de luy donner quelque subside afin de en aucune partie la relever de ladite despence et afin aussi de l'encourragier pour l'advenir résister de plus en plus aux envahyes dudit ennemi de nostre foy, lequel est bien apparant de retourner, attendue la grande puissance qu'il a et la petitte résistence que luy ont jusques ores fait les autres chrétiens, $\mathbf{n}^{\prime}$ est que Sadite $\mathrm{Ma}^{\mathrm{té}}$ y pourvoye.

Et à ceste bonne et très urgente cause, Sa Sainteté a imposé à tout le clergié des pays de pardeça ung subside de la moitié de la vraye valeur de tous les fruitz des éveschiéz, monastères, dignitéz, prévostéz, prébendes, bénéfices et offices ecclésiastiques, exemptz et non exemptz, de quelque qualité ou condition qu'ilz soyent, et par qui que soyent possessees, exceptéz tant seullement les cardinaulx, les monastères des mendians et les chevaliers de Saint Jehan de Jérusalem, lesquelz à raison de leurs biens ou bénéfices qu'ilz possessent ne seront contribuables. Mais quant à tous autres et aussi ceulx qui auront aucuncs pensions assignees sur lesditz dignitéz, bénéfices ou offices, ils y seront tenuz satisfaire et payer ladite moitié de la vraye valeur en deux ans.

Parquoy ledit doyen les exhortera à ce que comme bons et loyaulx tant audit saint siège que à Sadite $\mathrm{Ma}^{\text {té }}$ ilz se rendent voluntaires au payement dudit subside chacun selon son contingent, et avec ce qu'ilz feront leur debvoir ce redondera à la préservation de leurs personnes et église et le tiendra Sadite $\mathrm{Ma}^{\text {té }}$ pour service très agréable.

Et par ce que Sadite Maté désire autant supporter ledit clergié qu'il est possible, afin que plus commodieusement il puist payer, sera content que les payemens se facent à quatre termes par égalle portion dont le premier escherra à la Saint Jehan Baptiste prochainement venant et le second au Noël enssuyvant XVcXLII et les autres deux derniers termes à la Saint Jehan Baptiste et au Noël enssuyvant XLIII. 
Ledit doyen remonstrera en particulier et par divises aux principaulx dulit clergié que le roy de France, lequel n'a aucune guerre signamment contre les infidèles, depuis naguerres a imposé de son auctorité et sans demander de consentement du Saint Siège apostolique, ung subside d'aucunes décimes sur tous les bénéfices de France et en a fait faire les cotisations ou taux et iceulx exécuter par main forte contre les déloyaux et opposans. Ce que l'empereur, ores qu'il eust eu grande occasion de ce attempter pour les raisons avantdictes, touttesfoiz, il n'a voulu ce faire, ains comme bon prince catholique a voulu dresser l'affaire par le moyen dudit Saint Siège selon que par droit raison et honnesteté il appartient.

Et afin que de tant mieulx ledit clergié cognoisse l'intencion dudit saint père, ledict doyen de Nyvelle fera lire (sa proposition achevee) entièrement tout le proces fulminé auquel les bulles sont inserees au long, lesquelles n'est besoing autrement exhiber attendue la clause mise en fin desdites bulles que ung transumpt faict par personnaige constitué en dignité devant notaire et tesmoings debvra avoir autant de foy que l'original.

Finalement ledit doyen ayant achevé sa proposition délivrera au notaire qu'il mènera avecq lui ledit proces fulminé et le requerra et de la part de l'empereur luy ordonnera que en vertu de la clause ceterum contenue audit proces il face insinuation dudit proces fulminé et admoneste tous ceulx dudit clergié de satisfaire es jours avantditz au taux qui leur sera envoyé.

S'il par aventure estoit obicé audit doyen par le clergié qu'ilz ne vouldroyent accepter lesdits termes attendu que par la teneur desdites bulles ilz ne sont tenuz que payer ledit subside endedans deux ans, qui se pourroit entendre en la fin du premier an et la fin du second par esgale portion, il pourra respondre que les termes mis par $\mathrm{Sa} \mathrm{Ma}^{\text {té }}$ comme dit est ont esté apposé en faveur desditz du clergié, lesquelz payeront plus aisé et plus facillement ung quart dudit subside que la moitié. Et aussi prendant regard à la date desdites bulles qui sont du XIXe de novembre, il fauldroit qu'ils payassent l'entière moitié dudit subside au XIXe jour de novembre ce que leur seroit plus grief que de payer partie en fin de décembre enssuyvant, joint qu'il est besoing à Sa Ma ${ }^{\text {té }}$ pour subvenir à aucuns grans affaires concernans la républicque des pays de pardeça avoir bien tost quelque bonne somme. Parquoy fait à espérer que lesditz du clergié esdits termes ne feront difficulté.

Si lesditz du clergié demandent qui tauxera les fruitz, ledit doyen respondra qu'ilz payeront selon le taux qui leur sera envoyé et que le taux se fera selon la bulle et que en ce on leur ne fera nul tort.

S'ilz obicoyent que les receveurs de l'empereur ne debvroyent avoir la collecte des deniers dudit subside, attendu que le révérendissime archevesque de Palerme est député collecteur par lesdites bulles et que les officiers des évesques ont accoustumé lever les deniers et les payer aux receveurs, se respondera que ledit archevesque s'est déporté de ladicte collecte laquelle, veu qu'elle doibt tourner au prouffit de Sa $\mathbf{M a}^{\text {té }}$, se peult ceullier par tel qu'il plaira à Icelle ordonner et commettre, comme a esté fait en cas semblable 
du subside de l'an XXXII, ce que se fera à moindre despence et empeschement par lesdits receveurs qui seront tenuz despescher les particuliers payans et leur bailler quictance sans riens prendre que par lesdits officiers des évesques et sera évité circuit de bailler les deniers en pluisieurs mains.

Et au résidu ledit doyen fera tout ce que pour le bien et advancement de l'affaire il cognoistra estre utille ou de besoing et selon que la royne a en luy parfaite confidence. Fait à Byns, le VIIIme jour de janvier XV'XLI.

Filips Nigri, kanselier van de Orde van het Gulden Vlies, benoemt Nicolas Nicola tot collecteur van het kerkelijk subsidie in Brabant.

Namen, 16 september 1542 ; kopie.

Brussel, A.R.A., Rekenk., nr. 15740, fo. 2.

Philippe Nigri, chancelier de l'Ordre, doyen de l'église collégialle Saincti Goulle à Bruxelles, à tous ceulx qui ces présentes verront, salut. Comme il ait pleu à nostre saint père le pape moderne Paul, troisièsme de ce nom, nous députer collecteur du subside naguerres accordé à l'Impérialle $\mathbf{M a}^{\text {té }}$ sur les biens des églises, monastères, collèges, couventz et personnes ecclésiastiques de ses pays d'embas selon que es bulles sur ce depeschees peult plus amplement apparoir, et obstant aulcuns aultres affaires ne puissions bonnement entendre à faire le taux desdits biens d'église et bénéfices ne a la collectation des sommes que se debvront recepvoir, à ceste cause nous confians plainement en la prudence, léaulté et bonne dilligence de maistre Nicolas Nicolaï, recepveur général des aydes de Brabant, l'avons par cestes subdélégué et commis pour au lieu de nous et au profit de sadite $\mathbf{M a}^{\text {té }}$ envoyer à chacun des bénéficiés, collèges, monastères ou couvents scituéz ou ayans biens es diocèses resortissans audit pays de Brabant son taux tel que par aultres commissaires fust faict en l'an $\mathrm{XV}^{\mathrm{c}}$ trente trois, lequel taux luy avons baillé soubz nostre signe manuel pour icelluy recepvoir et exécuter réallement et de faict aux termes contenuz esdites bulles comme en tel cas il convient et appartient, promettant avoir pour estable, ferme et agréable tout ce que par ledit recepveur en ce que dessus et es dépendences sera faict et besoigné. En tesmoing de ce, nous avons faict mectre nostre scel à ses présentes. Donné en la ville de Namur, le XVIme jour de septembre, l'an de grace mil cincq cens quarante deux. Et soubzsigné $\mathrm{Ph}$. Nigri.

Collationné aux lettres originaulx et trouvé concorder à icelluy demouré es mains dudit receveur. 
Robert de Bouloingne, ontvanger-generaal van Financiën, ontlast Nicolas Van der Laen, ontvanger van het kerkelijk subsidie in Mechelen, voor een som van vijftienhonderd pond.

18 novembre 1546 ; origineel.

Brussel, A.R.A., Rekenk., nr. 16913.

Je, Robert de Bouloingne, conseillier et receveur général des finances de l'empereur, confesse avoir recue de Nicolas Van der Laen, receveur du terroir de Malines et commis à recevoir et faire venir les deniers du subside, accordé audit seigneur empereur par nostre saint père le pape sur les gens d'église et clergié du diocèse de Cambray, sortissant es limites de son office, la somme de quinze cens carolus d'or, de vingt pattars pièce, sur ce qu'il pourra devoir à Sa Maté, à cause du premier terme d'icellui subside, eschéant au Noël prouchain venant, en deniers paiéz à aucuns marchans d'Anvers, entantmoins de soixante treize mil semblables carolus d'or, comprins le frait que Sadite $\mathrm{Ma}^{\text {té }}$ fait présentement lever à finance, à paier à la foire de pasques $\mathrm{XV}^{\mathbf{c}}$ quarante sept, de laquelle somme de $\mathrm{XV}^{\mathrm{c}}$ karolus d'or dudit pris, je suis content, tesmoing mon séing manuel cy mis, avecq le signet ordonné sur le fait desdites finances, et les séingz manuelz des chiefz, trésorier général et commis d'icelles. Le XVIII e jour de novembre $\mathrm{XV}^{c}$ quarante six.

(getekend) : Loys de Praet, Cornelissen, Claissone, Boisot.

\section{$\mathrm{V}$}

De Raad van Financiön beveelt aan Nicolas Van der Laen, collecteur van het subsidie in Mechelen, de staat van dit subsidie voor te leggen.

Brussel, 31 mei 1548 ; origineel.

Brussel, A.R.A., Rekenk., nr. 16913.

Les chiefs, trésorier général et commis des finances. Très chier seigneur et espécial amy.

Pour ce que le dernier terme du présent subside ecclésiastique doit escheoir à la St. Jehan prouchain, et que la royne désire savoir l'estat d'icelle, nous vous requerons et de par $\mathrm{Sa} \mathrm{Ma}^{\text {té }}$ ordonnons que le $\mathrm{VI}^{\mathrm{e}}$ jour du mois de juing prouchain, vous vous trouvez vers nous pour faire ledit estat, appartant avecq vous vostre compte du dernier subside, levé es années XLII et XLIII, ensemble telz enseignemens dont vous vouldres vériffier la despence de vostre estat, et en ce n'y faictes faulte.

A tant, très chier seigneur et espécial amy, nostre seigneur soit garde de vous.

De Bruxelles, au bureau des finances, le dernier de may 1548. (Getekend) : Vandenberge. 
(in dorso): A nostre très chier seigneur et espécial amy Nicolas Van der Laen, receveur de Malines et commis à la recepte du subside audit quartier.

Le commis du receveur de Malines, obtempérant au contenu des lettres de messeigneurs des finances cy dessus, s'est trouvé en ceste ville pour faire son estat du subside, enquoy faisant il a vacqué trois jours, desquelz il sera paié par les mains dudit receveur de Malines, au pris de douze pattars par jour, et en rapportant avecq cestes quictance sur ce servant, il luy sera passé en compte là et ainsi qu'il appartiendra.

Faict au bureau des finances, à Bruxelles, le VII ${ }^{e}$ de juing, $\mathrm{XV}^{\mathrm{c}}$ quarante huit.

(getekend) : Cornelissen, De Lalaing, Claissone, Longin. 